\title{
Seeking the Source of Transience for a Unique Magnetic Field Pattern That Completely Dissolves Cancer Cells in Vitro
}

\author{
Lukasz M. Karbowski, Nirosha J. Murugan, Stanley A. Koren, Michael A. Persinger \\ Behavioural Neuroscience and Biomolecular Sciences Programs, Laurentian University, Sudbury, Canada \\ Email: mpersinger@laurentian.ca
}

Received 8 July 2015; accepted 18 August 2015; published 21 August 2015

Copyright (C) 2015 by authors and Scientific Research Publishing Inc.

This work is licensed under the Creative Commons Attribution International License (CC BY).

http://creativecommons.org/licenses/by/4.0/

(c) (i) Open Access

\section{Abstract}

Purpose: Exposure to a particular pattern of weak ( $\sim 3$ to $5 \mu \mathrm{T}$ ) magnetic fields produced by computer-generated point durations within three-dimensions completely dissolved malignant cancer cells but not healthy cells. Biomolecular analyses and confocal microscopy indicated excessive expansion followed by contraction contributed to the "explosion" of the cell. However, after months of replicable effects, the phenomenon slowly ceased. Considering the potency of the complete dissolution of cancer cell lines after 5 days of 6.5-hour daily exposures and the implications for human treatment, the potential source of the disappearance of the effect was pursued by summarizing all of the 50 experiments and assessing the likely etiologies. Materials and Methods: B16-BL6, MDAMB 231 and MCF7 malignant cells and HSG, a non-malignant cell line, were exposed to a sham-field condition or to a specific pattern of computer-generated magnetic fields produced from converting different voltages, each with point durations of $3 \mathrm{~ms}$ to 3-D magnetic fields. Conclusion: The specific serial presentation of the two field patterns (one frequency modulated; the other amplitude and frequency modulated) completely dissolved malignant cells but not normal cells within a "zone" within the exposure volume at the conjunction of the three planes of the applied magnetic fields. The affected cells underwent massive melanin production, expansion, contraction and "beading" of submembrane actin structures before fragmentation within this zone. However, this powerful all-or-none phenomenon may have been disrupted by moving the cells, excess mechanical agitation during exposure, or non-optimal point durations of the field parameters. Indirect effects from communication signals (WIFI) through line currents that operated the incubators could not be excluded.

\section{Keywords}

Cancer Cells, Normal Cells, Point Duration Magnetic Fields, Dissolution Effect, MicroTesla 


\section{Introduction}

The classic Greek philosopher Heraclitus is credited with stating that "one can never step into the same river twice". The operation if it were homogeneously valid would eliminate the potential for replication, the most essential property of knowledge derived from experimentation. Most models of physics depend upon the assumption of constancy for parameters that determine interactions between matter and energy superimposed within space. However, the earth has not been in the same space during human history as the solar system orbits the galactic center approximately once every 250 million years. If even a subset of terrestrial phenomena is influenced by the intrinsic changes in spatial structural, then the ephemeral reliability of multiple observations in a relatively narrow temporal band may originate from processes other than random or spurious variation. The unique features of biological systems with respect to electromagnetic field-energetic interactions have been reviewed by Cifra et al. [1]. The quantifiable relationships between chemical dynamics of cell-relevant systems and the specificity of the applied fields have been reiterated by many researchers [2]-[4].

Within the domains of cancer research, there have been multiple reports of effects over the centuries that appear to be very efficacious within the specific laboratory or historical period that ultimately or "suddenly" lost their potency. The most typical attributions have involved experimenter incompetence, changes in quality of reagents and equipment, or anomalous cell lines. Although all of these factors are likely to have been present in many of the failures to replicate [5], they are still post hoc explanations and attributions rather than experimental proofs. The actual combination of causal variables that result in elimination or attenuation of malignant cell growth without adversely affecting normal cells may not be identified in our lifetimes. However, a tradition of systematically reporting the most powerful, although transient, treatment effects in the scientific literature may ultimately contribute to the solution.

There are several studies that have demonstrated a moderate slowing of cell growth of malignant cells when they are exposed for one hour to a few hours per day to patterned magnetic fields with intensities within the microTesla to milliTesla range [6]-[8]. Murugan et al. [9] had found that exposing planaria for $6.5 \mathrm{hr}$ per day for 5 days to one frequency-modulated pattern that also produced analgesia in invertebrates and vertebrates produced no conspicuous effects. However, on the fifth day when the worms were exposed for an additional 6.5 hours to a very complex magnetic pattern that was an accelerated amplitude modulated form, there was complete dissolution of the worms within about two hours [9].

The effect did not occur if this accelerated pattern was presented first for five days and then the frequencymodulated pattern was presented. The proportion of dissolution of the planaria was also a function of the duration of the antecedent exposure to the fields on the last day as well as field intensity. Such directionality, similar to the variable efficacy of $\mathrm{L}$ and $\mathrm{R}$ stereoisomers, has been found for a specific pattern that produces analgesia, cell growth, and infusion of calcium into cells [10] [11]. Presentation of the same pattern but in reverse sequence resulted in no effect. When we exposed mouse melanoma cells to this protocol, we measured complete elimination of cells on the fourth and fifth days after the treatment began. The effect was conspicuous and displayed an intensity threshold. This was manifested as an area at the interface of the three-planes of magnetic field application with cell absence surrounded by relatively normal cells. Despite dozens of replications over several months, this powerful and potentially clinically applicable effect slowly attenuated over a period of about two months. Here we present the general conditions and characteristics of this phenomenon.

\section{Methods}

\subsection{General Experimental Protocol}

For all 50 experiments the preparation, extraction and handling of cells were as similar as possible and involved at least three different experimenters. The primary cell line was a mouse melanoma (B16-BL6). Because of the initial success other lines such as MDA MB 231, MCF 7 and HSG cells (from American Type Culture Collection) were tested. As shown in Table 1 there were a total of 50 experiments completed over a period spanning three years $(2012,2013$, and 2015). 
Table 1. Results of all of the experiments that include the dates, parameters, cell type and effect (\% dropout) of malignant cells for this specific magnetic field configuration.

\begin{tabular}{|c|c|c|c|c|c|}
\hline \multicolumn{6}{|c|}{ MuKarb in Vitro Experiments } \\
\hline Start Date & End Date & Experiment & Cell & Effect & Point Duration \\
\hline \multicolumn{6}{|c|}{ Year: 2012} \\
\hline $14-\mathrm{Feb}$ & $18-\mathrm{Feb}$ & 5 day mukarb & $\mathrm{B} 16$ & $100 \%$ drop & $3 / 3 \mathrm{msec}$ \\
\hline 21-Feb & $25-\mathrm{Feb}$ & 5 day mukarb & $\mathrm{B} 16$ & $100 \%$ drop & $3 / 3 \mathrm{msec}$ \\
\hline 04-Mar & 09-Mar & 5 day mukarb & $\mathrm{B} 16$ & $100 \%$ drop & $3 / 3 \mathrm{msec}$ \\
\hline 11-Mar & 16-Mar & 5 day mukarb & $\mathrm{B} 16$ & $100 \%$ drop & $3 / 3 \mathrm{msec}$ \\
\hline 19-Mar & 24-Mar & 5 day mukarb & $\mathrm{B} 16$ & $100 \%$ drop & $3 / 3 \mathrm{msec}$ \\
\hline 26-Mar & 30-Mar & 5 day mukarb & $\mathrm{B} 16$ & $100 \%$ drop & $3 / 3 \mathrm{msec}$ \\
\hline 03-Apr & 07-Apr & 5 day mukarb & B16 & $100 \%$ drop & $3 / 3 \mathrm{msec}$ \\
\hline 23-Apr & 28-Apr & 5 day mukarb & $\mathrm{B} 16$ & $100 \%$ drop & $3 / 3 \mathrm{msec}$ \\
\hline 13-May & 14-May & 1 day mukarb & $\mathrm{B} 16$ & $15 \%$ drop & $3 / 3 \mathrm{msec}$ \\
\hline 04-Jun & 06-Jun & 3 day mukarb & $\mathrm{B} 16$ & $40 \%$ drop & $3 / 3 \mathrm{msec}$ \\
\hline 11-Jun & 15-Jun & reverse mukarb & $\mathrm{B} 16$ & $0 \%$ drop & $3 / 3 \mathrm{msec}$ \\
\hline 05-Jul & 09-Jul & reverse mukarb & $\mathrm{B} 16$ & $0 \%$ drop & $3 / 3 \mathrm{msec}$ \\
\hline 29-Jun & 03-Jul & 5 day mukarb & $\mathrm{B} 16$ & $100 \%$ drop & $3 / 3 \mathrm{msec}$ \\
\hline 12-Jul & 16-Jul & 5 day mukarb $-1 \mathrm{hr}$ & $\mathrm{B} 16$ & $0 \%$ drop & $3 / 3 \mathrm{msec}$ \\
\hline 12-Jul & 16-Jul & 5 day mukarb & B16 & $100 \%$ drop & $3 / 3 \mathrm{msec}$ \\
\hline 19-Jul & 20-Jul & 1 day mukarb & $\mathrm{B} 16$ & $15 \%$ drop & $3 / 3 \mathrm{msec}$ \\
\hline 24-Jul & 26-Jul & 3 day mukarb & $\mathrm{B} 16$ & $40 \%$ drop & $3 / 3 \mathrm{msec}$ \\
\hline 11-Apr & 15-Apr & 5 day mukarb & MDA MB 231 & $100 \%$ drop & $3 / 3 \mathrm{msec}$ \\
\hline 18-Apr & 22-Apr & 5 day mukarb & MDA MB 231 & $100 \%$ drop & $3 / 3 \mathrm{msec}$ \\
\hline 28-Jul & 01-Aug & 5 day mukarb & MDA MB 231 & $100 \%$ drop & $3 / 3 \mathrm{msec}$ \\
\hline 03-Aug & 08-Aug & 5 day mukarb & MDA MB 231 & $100 \%$ drop & $3 / 3 \mathrm{msec}$ \\
\hline 30-Apr & 04-May & 5 day mukarb & MCF 7 & $67 \%$ drop & $3 / 3 \mathrm{msec}$ \\
\hline 07-May & 11-May & 5 day mukarb & MCF7 & $59 \%$ drop & $3 / 3 \mathrm{msec}$ \\
\hline 18-May & 22-May & 5 day mukarb & MCF7 & $60 \%$ drop & $3 / 3 \mathrm{msec}$ \\
\hline 25-May & 29-May & 5 day mukarb & B16 & $100 \%$ drop & $3 / 3 \mathrm{msec}$ \\
\hline 12-Jul & 16-Jul & 5 day mukarb & $\mathrm{B} 16$ & $100 \%$ drop & $3 / 3 \mathrm{msec}$ \\
\hline 18-Jul & 22-Jul & 5 day mukarb & $\mathrm{B} 16$ & $100 \%$ drop & $3 / 3 \mathrm{msec}$ \\
\hline 19-Mar & 24-Mar & 5 day mukarb & HSG & $0 \%$ drop & $3 / 3 \mathrm{msec}$ \\
\hline 26-Mar & 30-Mar & 5 day mukarb & HSG & $0 \%$ drop & $3 / 3 \mathrm{msec}$ \\
\hline 03-Apr & 07-Apr & 5 day mukarb & HSG & $5 \%$ drop & $3 / 3 \mathrm{msec}$ \\
\hline 12-Aug & 16-Aug & 5 day mukarb & B16 & $35 \%$ drop & $3 / 3 \mathrm{msec}$ \\
\hline 20-Aug & 24-Aug & 5 day mukarb & B16 & $35 \%$ drop & $3 / 3 \mathrm{msec}$ \\
\hline 26-Aug & 30-Aug & 5 day mukarb & B16 & $20 \%$ drop & $3 / 3 \mathrm{msec}$ \\
\hline 04-Sep & 08-Sep & 5 day mukarb & B16 & $25 \%$ drop & $3 / 3 \mathrm{msec}$ \\
\hline 09-Sep & 13-Sep & 5 day mukarb & B16 & $0 \%$ drop & $3 / 3 \mathrm{msec}$ \\
\hline 25-Sep & 29-Sep & 5 day mukarb & B16 & $0 \%$ drop & $3 / 3 \mathrm{msec}$ \\
\hline $11-\mathrm{Nov}$ & $15-\mathrm{Nov}$ & 5 day mukarb & B16 & $0 \%$ drop & $3 / 3 \mathrm{msec}$ \\
\hline 19-Nov & 23-Nov & 5 day mukarb & B16 & $0 \%$ drop & $3 / 3 \mathrm{msec}$ \\
\hline 10-Dec & 14-Dec & 5 day mukarb & B16 & $0 \%$ drop & $3 / 3 \mathrm{msec}$ \\
\hline
\end{tabular}




\begin{tabular}{|c|c|c|c|c|c|}
\hline \multicolumn{6}{|c|}{ Continued } \\
\hline \multicolumn{6}{|c|}{ Year: 2013} \\
\hline 14-Jan & 18-Jan & 5 day mukarb & B16 & $0 \%$ drop & $3 / 3 \mathrm{msec}$ \\
\hline 17-Mar & 22-Mar & 5 day mukarb & B16 & $0 \%$ drop & $3 / 3 \mathrm{msec}$ \\
\hline 24-Mar & 28-Mar & 5 day mukarb & B16 & $0 \%$ drop & $3 / 3 \mathrm{msec}$ \\
\hline \multicolumn{6}{|c|}{ Year: 2015} \\
\hline 20-Apr & 24-Apr & 5 day mukarb & B16 & $35 \%$ drop & $3 / 3 \mathrm{msec}$ \\
\hline 27-Apr & 01-May & 5 day mukarb & B16 & $20 \%$ drop & $3.25 \mathrm{msec}$ \\
\hline 04-May & 08-May & 5 day mukarb & B16 & $30 \%$ drop & $0.1 / 0.1 \mathrm{msec}$ \\
\hline 04-May & 08-May & 5 day mukarb & B16 & $25 \%$ drop & $3.38 \mathrm{msec} / 3.38 \mathrm{msec}$ \\
\hline \multicolumn{6}{|c|}{ Biomolecular Analysis: 2012} \\
\hline 27-Feb & & confocal & B16 & equal to camptothecin & $3 / 3 \mathrm{msec}$ \\
\hline 28-Mar & & phalloidin & B16 & positive actin staining & $3 / 3 \mathrm{msec}$ \\
\hline 17-Mar & & trypan blue test/morphology & B16 & enlargement and shrinking & $3 / 3 \mathrm{msec}$ \\
\hline
\end{tabular}

The B16-BL6 murine melanoma cells were cultured in vitro in DMEM (Dulbecco's Modified Eagle Medium) that contained $10 \%$ fetal bovine serum and antibiotics in a carbon dioxide environment at $37^{\circ} \mathrm{C}$ in standard incubators. Plates of cells were exposed to the "Thomas pulse" magnetic field pattern within the incubators for 6.5 $\mathrm{hr}$ per day for 5 days unless specified otherwise. On the fifth day an additional $6.5 \mathrm{hr}$ exposure to the second ("geomagnetic" pulse) occurred. Four experiments involved 1 day and 3 days to discern "duration" dependence. Each day, after the exposure, one of the plates was harvested to observe the effects. Cells were harvested following incubation with trypsin and collection by centrifugation at $2000 \mathrm{~g}$ for $10 \mathrm{~min}$. The pellets of cells were re-suspended in PBS containing 0.1\% trypan blue. Quantification was completed using a hematocytometer. For each sampled plate eight separate counts were obtained and averaged.

\subsection{Biochemical Measures-Acridine-Orange Confocal Microscopy (Detection of Apoptosis)}

B16-BL6 cells were cultured on glass coverslips and allowed to adhere for 24 hour at $37^{\circ} \mathrm{C}$. The cells were exposed to sham or MuKarb-EMF for $6.5 \mathrm{hr}$ per day with the geomagnetic component of the tandem field sequence presented only on the $5^{\text {th }}$ day. After treatment, the cells were collected 6 hours post-treatment on days 1 , $2,3,4$, or 5. B16-BL6 cells were also treated with $6 \mu \mathrm{g} / \mathrm{ml}$ of camptothecin and collected 6 hours post-treatment. This procedure was employed as a positive control for apoptosis. The cells were stained with $100 \mathrm{mg} / \mathrm{ml} \mathrm{ac}-$ ridine orange (Sigma Aldrich) for $5 \mathrm{~min}$ and then stained with $100 \mathrm{mg} / \mathrm{ml}$ of ethidium bromide (Sigma Aldrich) for $5 \mathrm{~min}$. The coverslips were washed in PBS, gently mounted onto a glass slide, and sealed with clear nail polish. Fluorescence was visualized by a LSM510 microscope using the $488 \mathrm{~nm}$ laser for activation and Fset 17 (detection $515-585 \mathrm{~nm}$ ) for acridine orange and Fset 28 (detection $617 \mathrm{~nm}$ ) for ethidium bromide (acridine orange excitation at $502 \mathrm{~nm}$ and emission at $526 \mathrm{~nm}$ and ethidium bromide excitation $510 \mathrm{~nm}$ and emission 595 $\mathrm{nm})$.

\subsection{Biochemical Measures-Phalloidin Confocal Microscopy (Actin Detection)}

B16-BL6 cells were cultured on glass coverslips and allowed to adhere for 24 hour at $37^{\circ} \mathrm{C}$. The cells were exposed to sham or MuKarb-EMF with the geomagnetic component of the tandem field sequence presented only on the $5^{\text {th }}$ day. After treatment, the cells were collected 6 hours post-treatment on days 1, 2, 3, 4, or 5. Cells were washed in PBS and fixed using formaldehyde (3.7\%) for 10 minutes at room temperature. The coverslips were washed with acetone at $-20^{\circ} \mathrm{C}$ for 5 minutes and stained with 5 uLAlexa Fluor ${ }^{\circledR} 488$ Phalloidin (Life Technologies) for $5 \mathrm{~min}$. Fluorescence was visualized using a LSM510 microscope.

\subsection{Equipment}

The equipment was similar to previous experiments. The exposure volume was a $10 \mathrm{~cm} \times 10 \mathrm{~cm} \times 10 \mathrm{~cm}$ plastic 
box (Figure 1(C)). Six (3 pairs) of solenoids that were modified reed relays (Radio Shack 275-0232 SPST5VDC, Contact rating: $0.5 \mathrm{~A}, 125 \mathrm{VAC}$, nominal current: $20 \mathrm{~mA}$ ). Each solenoid was $50 \Omega$ within which a small nail was inserted to enhance flux density and was contained within a plastic canister. Each canister containing the solenoid was placed at the midpoint of each wall of the box. The circuit was connected such that at any given time the two solenoids on opposite sides of the same plane were activated and the field was generated between these solenoids across the cells (Figure 2).

The plates were stacked 6 high in the middle of the box so that the cells were exposed to the interface of the three planes of the continuously generated magnetic fields. The average intensity of the magnetic fields in the center of the box as measured by a power meter was $26 \mathrm{mG}$ (range $26-29 \mathrm{mG}$ ) for both types of fields. For the Thomas pattern the field strength increased quasi-exponentially to $150 \mathrm{mG}$ (range 140 to $160 \mathrm{mG}$ ) adjacent to the solenoids as shown in Figure 2. The peak exposure in the plates along the edges was $\sim 50 \mathrm{mG}$. However the geomagnetic pattern produced an unusual gradient. Starting with the $26 \mathrm{mG}$ value in the center the strength $d i-$ minished towards the solenoids to about $18 \mathrm{mG}$ and then rapidly escalated to the increasing intensities as any given solenoid was approached. The perimeter for this sudden shift was about $4 \mathrm{~cm}$ from the center. Sham-field exposures involved placing the plates of cells in the same boxes except there was no field generation. The background power frequency magnetic fields $(60 \mathrm{~Hz})$ within the incubators were about $1.5 \mathrm{mG}$.

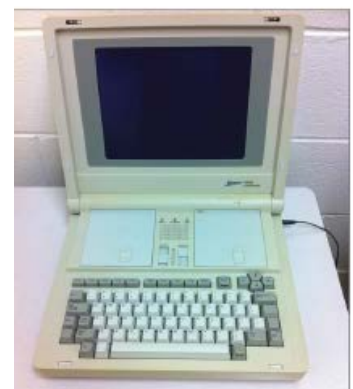

(A)

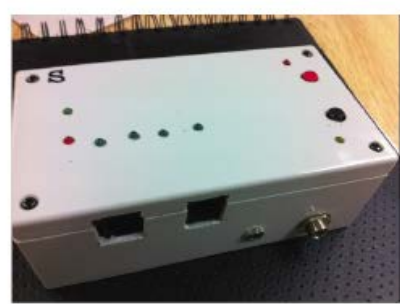

(B)

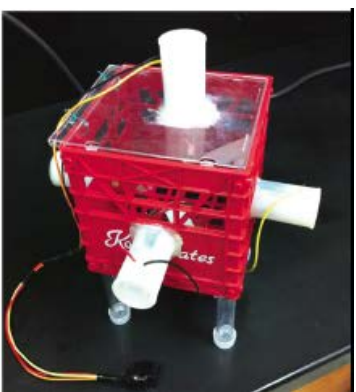

(C)

Figure 1. The three main components of the system from top to bottom: (A) the source computer (Zenith Laptop Model ZFL18193) containing the code (pattern) numerical sequence, (B) the DAC (digital to analogue converter) that transformers the numbers to voltages, and (C) the three orthogonal pairs of solenoids generating the magnetic field fields within which plates of cells are exposed.

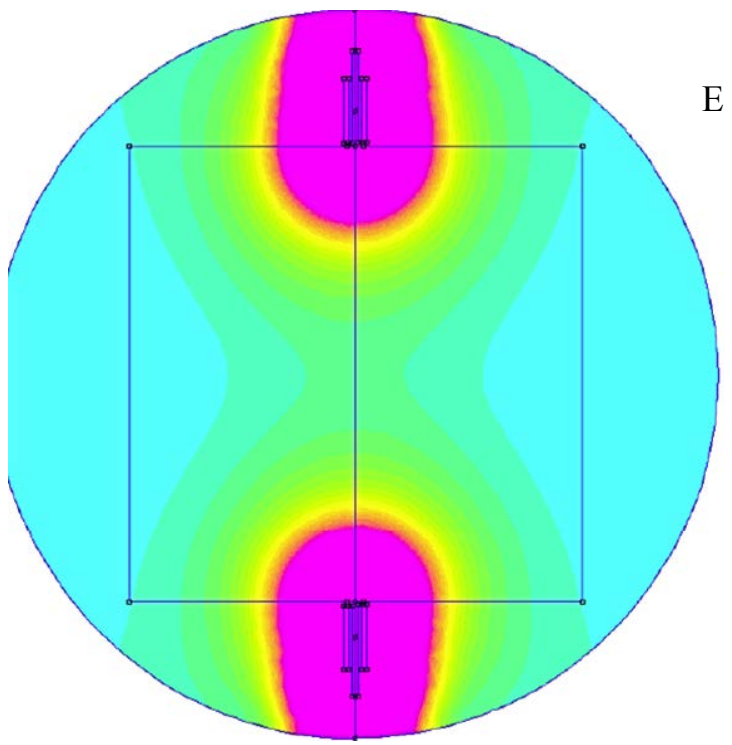

Figure 2. Colorized measurement of the strength of the Thomas pattern magnetic field generated between any two pairs of solenoids within the exposure area (thin line blue square). The cell dropout zone was approximately from the yellow corona of one solenoid to the other in all three dimensions. Fuchsia indicates maximum intensities 
The magnetic fields were generated by software and equipment developed by Koren and Persinger (U.S. Patent 6,312,376 B1: November 6, 2001; Canadian Patent No. 2214296). Essentially a series of numbers (in a column) from 1 through 256 were converted to voltages between -5 and $+5 \mathrm{~V}(127=0 \mathrm{~V})$ through a custom-constructed digital-to-analogue-converter (DAC). The Complex software was developed by the third author (Stanley A. Koren) and was organized such that any column of numbers could be transformed to specific voltages from a computer (Figure 1(A)). This allowed unlimited flexibility for the type of patterns that could be generated including those digitized from natural recordings of cell activity. The output of the DAC (Figure 1(B)) was delivered to the successive pairs of solenoids of the exposure boxes (Figure 1(C)).

The software was designed to control the point duration of each voltage. The value is the time allocated to generating a specific voltage (based upon the number between 0 and 257 being transformed) to the exposure device. The software also allowed programmable times between the presentations of patterns, that is the interstimulus or interpattern interval. Multiple previous experiments have shown that $3 \mathrm{~ms}$ point durations are most effective for slowing growth of cancer cells in vitro as well as in mice and for producing analgesia in rats that is equivalent to $4 \mathrm{mg} / \mathrm{kg}$ of morphine following only $30 \mathrm{~min}$ of exposure.

The "MUKARB" (Murugan-Karbowski) sequence is composed of two patterns. The first pattern, a frequency modulated field often described as the "Thomas pulse", has been shown to produce slowing of cancer cell growth rates and analgesia in vertebrates and invertebrates. It is composed of 849 points (i.e., numbers between 0 and 257) and is shown in Figure 3(A). The second pattern (composed of 5071 points) is shown in Figure 3(B). It was initially designed to imitate a sudden geomagnetic storm commencement by employing point durations of $69 \mathrm{~ms}$ such that a fundamental $7 \mathrm{~Hz}$ field was amplitude-modulated as well as (sub-harmonic) frequency-modulated over an approximately 6 min period. The spectral power densities are shown in Figure 3(C) and Figure 3(D). To obtain real frequency multiply the spectral frequency by $333 \mathrm{~Hz}$ (i.e., the Nyquist limit is $1 / 2$ or $167 \mathrm{~Hz}$ for 3 ms point durations). These patterns indicated that most of the energy for the "Thomas pulse" was between 8 and $25 \mathrm{~Hz}$ while the geomagnetic pulse was densely distributed across the low frequency band with a marked exponential increase approaching the Nyquist limit. When this pattern's point duration was set to $3 \mathrm{~ms}$ and pre-

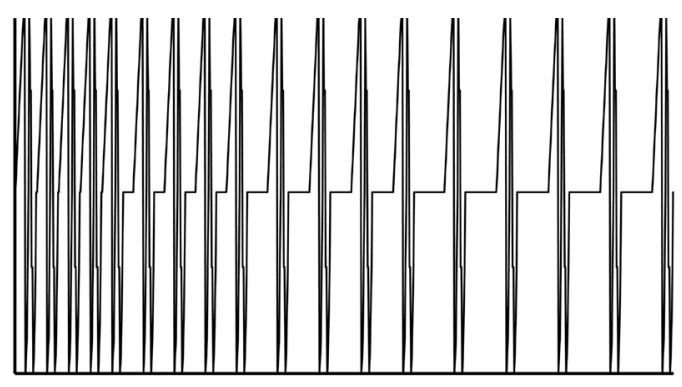

Time

(A)

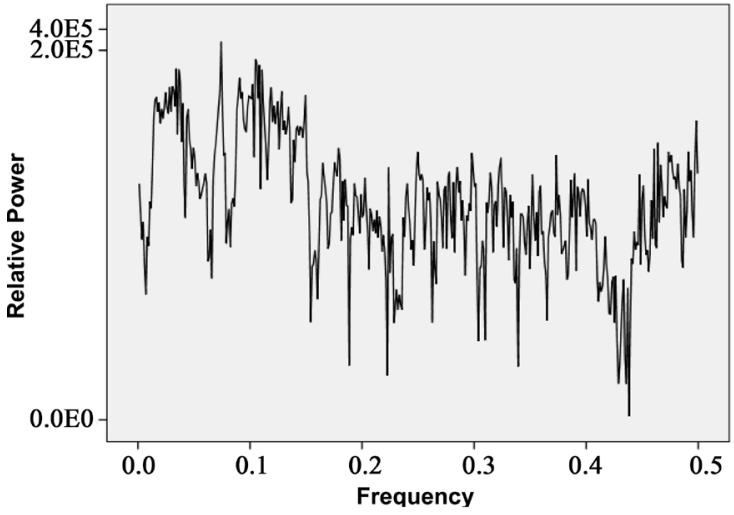

(C)

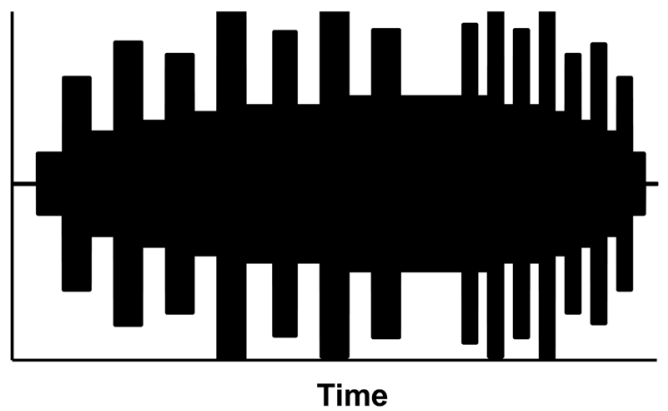

(B)

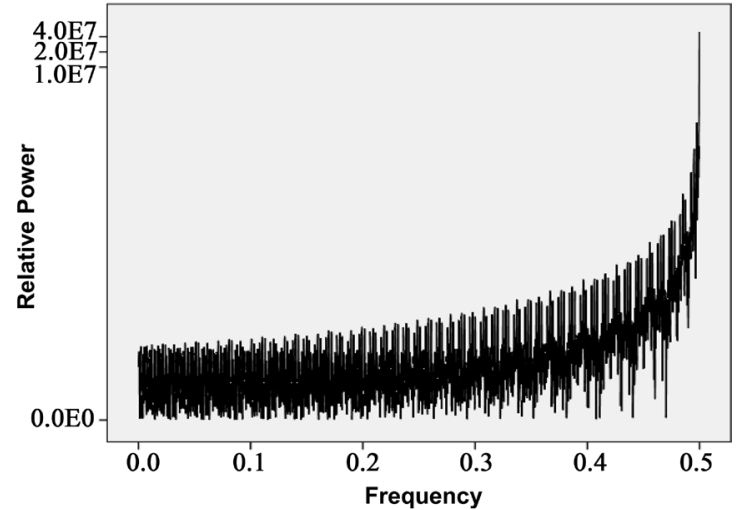

(D)

Figure 3. (A) "Thomas" or frequency-modulated pattern; (B) the geomagnetic pattern; (C) relative spectral power density for $\mathrm{A}$ as a function of spectral frequency; (D) relative spectral powr density for B as a function of spectral frequency. Real frequencies are obtained by multiplying base frequency by $333 \mathrm{~Hz}$. 
sented after the Thomas pattern exposures, Murugan et al. [9] found that planarian dissolved within two hours after the presentation of the field. Presenting the fields in reversed order or for briefer than optimal periods did not produce this effect.

In the present series of experiments over three years the MUKARB sequence was presented to different cell batches and types by different experimenters. In some experiments the MUKARB was reversed. The "geomagnetic" component was presented first and then the Thomas pattern was presented second. For some experiments the durations of exposures were less than 5 successive days. Following the failure to produce this robust effect additional manipulations of the point durations (year 2015) were completed to discern timing effects because precision has been shown to be critical.

\section{Results}

The summary of all of the results for the 50 experiments are shown in Table 1 . Between 14 February and 22 July 2012 the dropout rate from the MUKARB exposure was 100\% for the B16 and MDA MB 231 cells and about $65 \%$ for the MCF 7 cells. On the other hand HSG cells which are considered "non-malignant" showed no or minimal dropout during this period. This reiterated previous experiments that these patterned magnetic fields specifically affect cancer cells but not normal cells.

By $100 \%$ dropout, we mean there were no cells visible within this portion of the dishes. This is similar to the complete dissolution of the planarian we published previously [9]. Reversing the direction of the pattern ("reverse MUKARB") produced no dropout. Abbreviated exposures also produced less effect. After 22 July the effect began to diminish (August and September). During the remaining months of 2012 and the first part of 2013 the MUKARB sequence was no longer effective and was similar to sham-field treatments.

That the effect was geometric-intensity dependent is indicated in Figure 4. During the period of the optimal effect from the MUKARB sequence the initial dropout of the cells began in the areas of the dishes that were exposed to the central portion of the experimental field where all three planes intersected. The width of the "dissolution zone" was about $9 \mathrm{~cm}$. This width would overlap with the perimeter where the geomagnetic pattern shifts from its declining intensity from the center and suddenly increases (following the typical exponential curve) towards the solenoids.

\section{Biochemical Measures}

Melanin production in the cells exposed to the MUKARB when it was effective was visibly evident as shown in

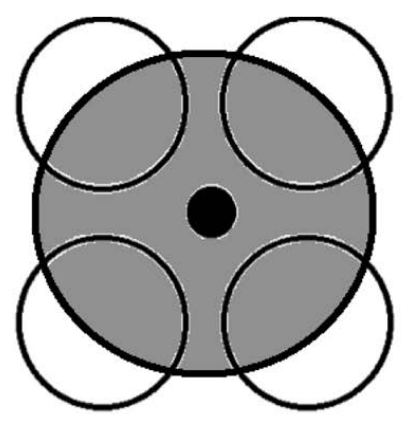

(A)
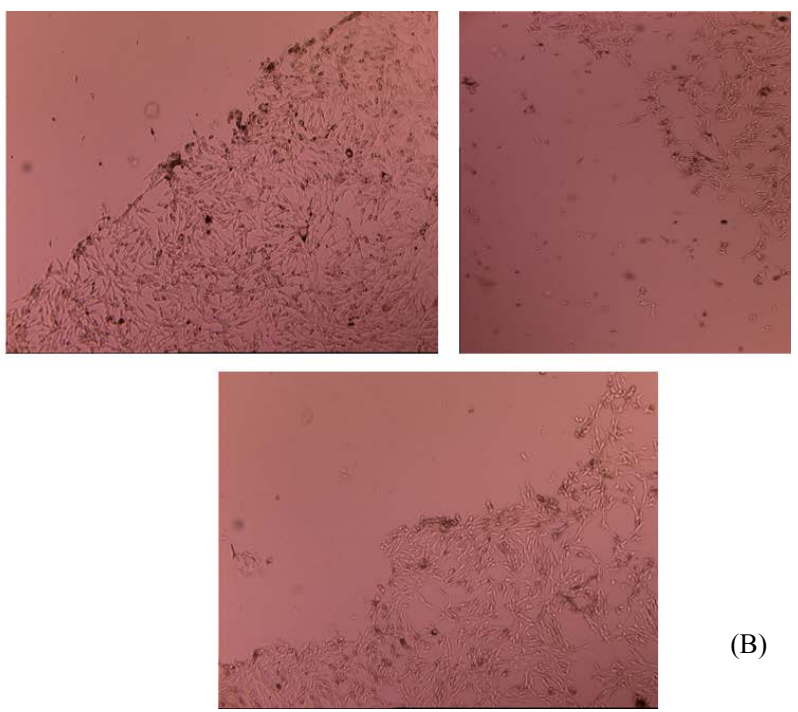

(B)

Figure 4. (A) Shows the position of the plates (6 stacked plates per quadrant) with respect to the central intersection of the magnetic fields generated across the three planes. The grey area (which extends about $4 \mathrm{~cm}$ from the center) indicates the zone where no cells were found. (B) Displays the drop out pattern $(40 \times)$ that was evident in the plates. Note the discrete boundaries for the difference between decimated cells and typical cell densities. 
Figure 5. There was a clear duration dependent increase in melanin production following exposure on the fifth day to the MUKARB sequence compared to the sham-exposed, camptothecin (the positive control for DNA damage) or either only the Thomas component or geomagnetic component of the MUKARB pattern. In other words the specific MUKARB sequence was required to produce the massive melanin production.

There was a clear time-dependence in the accumulation of melanin in the actual cells that was discernable after $15 \mathrm{~min}$ and maximized after $60 \mathrm{~min}$ as shown in Figure 6. It occurred only after the onset of the second (geomagnetic) field. Measurements were completed during the first hour because by the end of the $6.5 \mathrm{hr}$ exposure there were no cells remaining. Trypan blue measurement of the morphology indicated that enlargement of the cell by about $50 \%$ followed by rebound contraction by about $50 \%$ occurred within a period of about 2 hours. Note the marked melanin precipitant from cells $1 \mathrm{hr}$ after exposure to the final component of the MUKARB pattern.

The phalloidin stain (Figure 7) revealed a positive actin staining within the cells that was evident along the

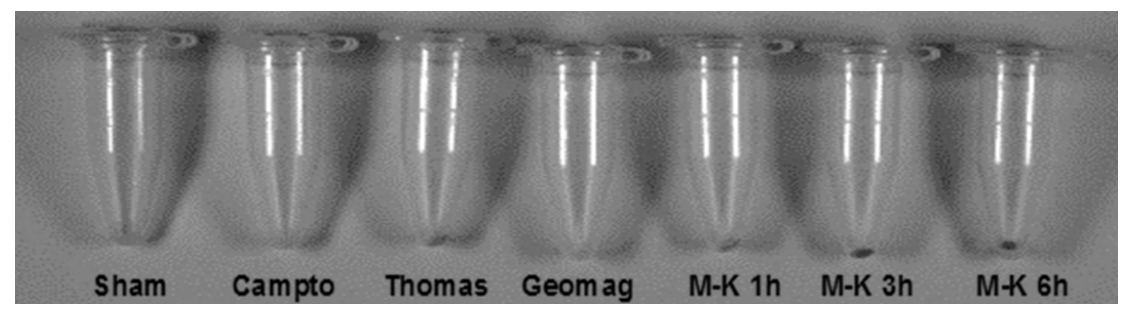

Figure 5. Presence of conspicuous melanin formation from precipitants of melanoma cells after exposure to various treatments including sham field, camptothecin, the Thomas only pattern, the geomagnetic pattern only and the combination (MUKARB or M-K) for $1 \mathrm{hr}, 3 \mathrm{hr}$ or $6 \mathrm{hr}$. Note the time duration increase in melanin precipitant in the pellet.
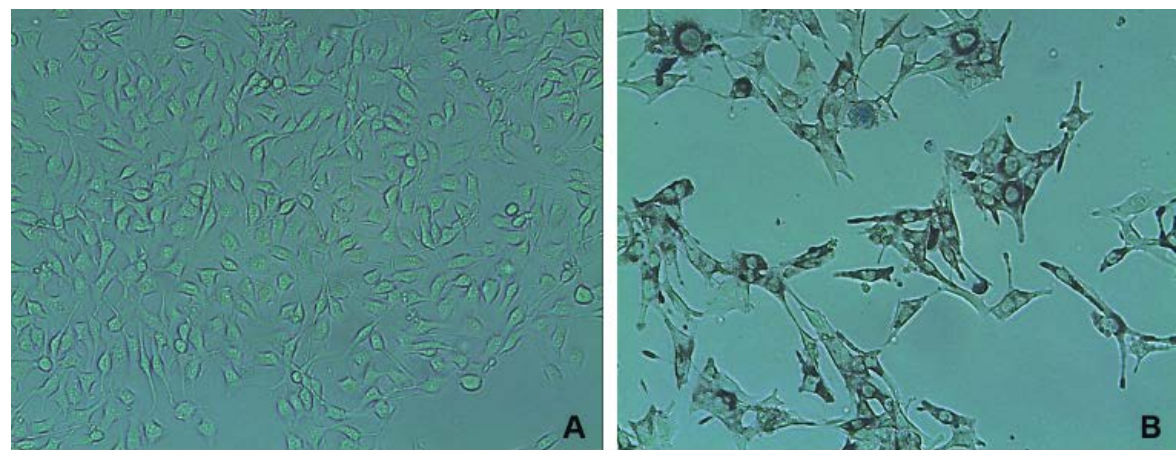

Figure 6. The appearance of melanin in melanoma cell increased as a function of time of exposure to the MUKARB magnetic pattern $(100 \times)$. Above (A) sham field exposed; (B) $60 \mathrm{~min}$ after exposure to the final component of MUKARB.
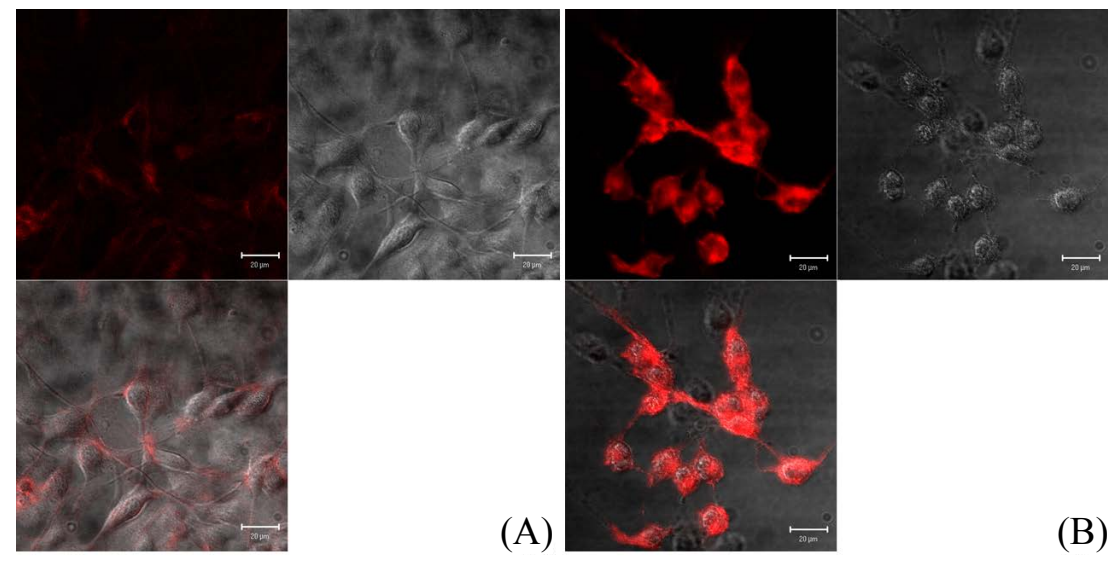

Figure 7. Fluorescence visualized for phalloidin using a LSM510 microscope for cells that have been exposed to the sham field ((A) left 3 panels) or to the MUKARB pattern ((B) right 3 panels). Red indicates marked actin staining. Horizontal line indicates $10 \mu \mathrm{m}$ (Magnification 100×). 

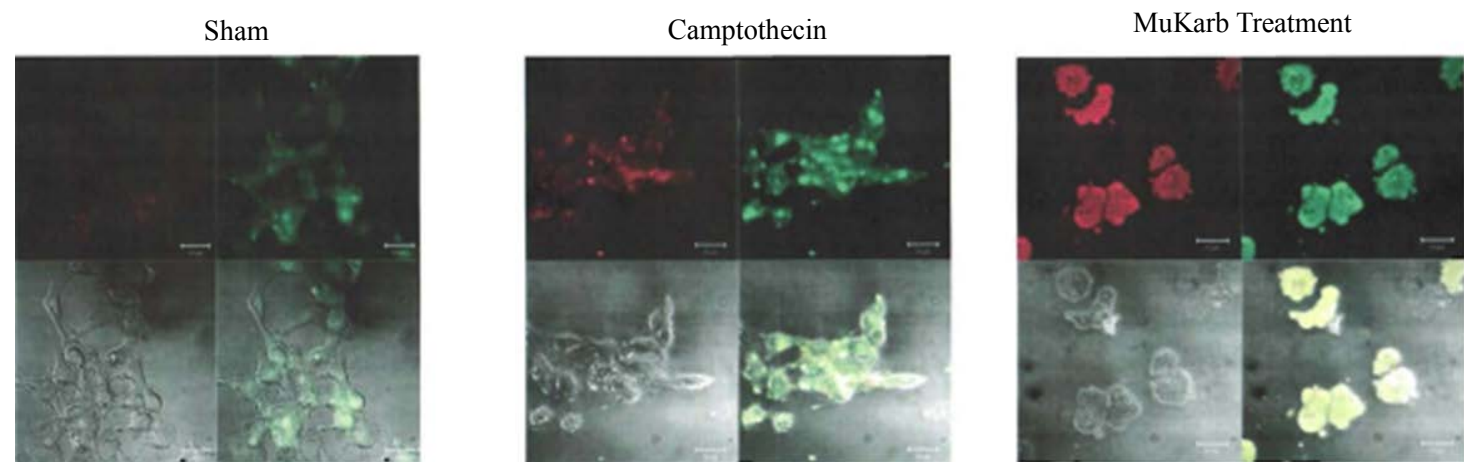

Figure 8. Acridine orange stain results for cells exposed to the sham field, the camptothecin treatment, or the MuKarb treatment. The "beading" of likely actin of the peripheral cytoskeleton is evident in the latter (magnifcation 100×).

insides of the plasma membranes as revealed by CONFOCAL microscopy. However unlike normal cells or sham-field exposed cells the indicator of actin staining revealed enhanced heterogeneity of density along the internal perimeter. The "smooth" distribution observed for normal cells was replaced with successive increments of short "widening" of the "ring" as if coalescence was beginning. This beading is most obvious with the acridine orange stain shown in Figure 8 as well as at low magnifications.

\section{Discussion}

We [8] [9] [11] [12] have been examining the effects of various patterns, phases, intensities, frequencies, and origins of magnetic fields upon biological systems for decades. The development of the personal computer and the specialized software by S. A. Koren that allowed the generation of innumerable sequences of voltages (and magnetic fields), each with specific point durations, significantly changed the flexibility for producing applicable electromagnetic patterns that could imitate those generated by natural processes. Our original research with relatively short duration patterns (about 1 to $2 \mathrm{~s}$ ) repeated over periods of $30 \mathrm{~min}$ to $60 \mathrm{~min}$ produced analgesia in rats [11] [13] that was equivalent to $4 \mathrm{mg} / \mathrm{kg}$ of morphine and was blocked by pharmacological agents known to antagonize mu receptors [11] and the nitric oxide correlates [13]. Similar effects were found with invertebrates during the same period of exploration by Thomas, Prato, Ossenkopp, Kavaliers and their colleagues [14].

The progress from single pattern exposures to tandem sequences of different patterns was a logical extension that produced powerful effects. Prenatal exposure of rats to a complex magnetic field composed of about 20 patterns (some repeated) resulted in conspicuous morphological changes in hippocampuses in adult brains [12]. When adult mice were exposed to this same pattern for several days, micro-array analyses indicated significant shifts in genes associated with the pathways involved with membrane and myelin integrity and formation. When a protocol, involving the same two patterns employed in the present experiments, was applied to planarian for several hours per day over 5 days, a conspicuous and complete dissolution of these worms occurred within hours of the initiation of the second pattern [9].

In a manner similar to the elicitation of powerful limbic seizures and brain damage in rats injected systemically with therapeutic concentrations of lithium followed 4 hours later by pilocarpine but not if the order of drug injection was reversed [15], reversing the Thomas-Geomagnetic order produced no dissolution of the worms [9]. The same treatment was applied to cancer cells. When the treatment was effective over several months, we found similar massive disruptions of cell integrity in cultures. Subsequent biochemical analyses revealed potential intracellular changes that would be consistent with the decimation of the entire cell within a defined perimeter at which the three planes of the applied magnetic fields intersected. When the order of the pattern was reversed, the cell morphology and biochemistry did not differ from sham field controls.

\subsection{Potential Mechanisms}

The results of the phalloidin stain following exposure to the MUKARB sequence were conspicuous. The typical thin "layer" of actin that we presume reflects the internal cytoskeleton often seen in normal and non-exposed cells was replaced with an emerging "beady" texture as if a series of discontinuities had been introduced into this layer's continuity. It appeared similar to what we [16] and others [17] had seen with traditional histological 
stains by light microscopy in the myelin in the long tracts in brains of patients and rats who had sustained massive impacts of mechanical energy to their skulls. This "beading" is called "retraction balls" and has been attributed to the result of the sudden contraction and expansion of the cerebral volume during the mechanical impact. Along the path of the pressure wave, there were discrete clusters of shrunken and darkly stained neuronal cell bodies containing marked "granulated" structures visible at $1000 \times$.

The trypan blue indicators were consistent with relatively quick enlargement and shrinkage of the cells following the onset of the second component of the MUKARB. We suggested that the "bead-like" nature of the phalloidin perimeter might reflect the analogue of "retraction balls" found in myelin and would support the microscopic observation that the cells underwent distention/contractions beyond the elastic limit of the actin-containing cytoskeleton. The phenomenon might be considered to be analogous to the long-term consequences of excessive extension of actin-myosin molecules in muscle fibers that resulted in anomalous changes in Z-lines that subsequently affected the tissue's capacity to display maximum displacement in response to interactions with ATP. This condition is often associated with the deposition of fine particles of calcium salts. In the cellular instance, the distention appears to have exceeded the tensile strength of these proteins resulting in micro-fragmentation or "bursting" of the cells.

\subsection{Potential Sources for Inconsistency of Effects and Limitations}

The reasons for the "slow" diminishment of this conspicuous effect are not clear. We consider at least four possibilities. The first involved the introduction of pervasive and dense wireless communication within the facility. Although one would expect that the incubators would behave as simulated "electrically shielded" Faraday cages, this may not be correct. Many facilities, including the one in which our experiments were conducted, superimpose (unknowingly or by design) the wireless signals within the peripheral shielding of the cables delivering the line current. We have measured these microwaves signatures through the protective covering of the lines from the power supplies (although they are grounded) that drive the DAC systems. It may be useful to remember that with a background of $10 \mathrm{~W} \cdot \mathrm{m}^{-2}$ from microwave appliances (which we measured in the laboratory where the experiments were completed) the energy across a cell with a cross-sectional area of $\sim 10^{-10} \mathrm{~m}^{2}$ is about a picoJoule per s. This is within the range of the energy per second utilized by the cell from glucose metabolism. Whether or not these energy sources would be interactive must still be discerned.

The second source is the role of thixotropic phenomenon as described by Verdel and Bukovec [18] Thixotropy refers to the slow increase in gel-like behavior of water, that is increased viscosity of a volume of water, when it is remains stable in the same place and usually in the dark. Mechanical processing such as movement of the plate or intrinsic vibrations from the environment diminishes this additional viscosity. Thixotropy develops spontaneously over time and is likely to involve the formation of structured networks of hydrogen bonds between ions in aqueous solution and the water molecules. The width of these networks ranges between 30 to 500 $\mathrm{nm}$ with a median of about $100 \mathrm{~nm}$. In other experiments Murugan et al. [19] found that exposure of spring water (but not double distilled water) sitting undisturbed in the dark for more than a week to the Thomas pattern resulted in marked increases (100 photons or about $20 \%$ more than sham field exposed) in photon emissions as measured by fluorescent spectrophotometry within the visible wavelength. The shift from about 390 to $409 \mathrm{~nm}$ involved a difference of about $10^{-20} \mathrm{~J}$. Spectral analyses of the enhanced photon counts across the $1 \mathrm{~nm}$ frequency band revealed a spatial periodicity of $10 \mathrm{~nm}$, the width of a membrane. Excessive mechanical agitation of the samples during transport to the laboratory eliminated the effect.

The third possible explanation is that the fidelity of the components of the DAC system, which transforms the columns of numbers to voltages and hence ultimately to the current that generates the magnetic fields within the solenoids, may be limited. The unique feature of this method of generating magnetic fields involves an optocoupler that if our assumptions are valid [20] results in superimposition of photons within the magnetic field within which the cells are exposed. There is accumulating evidence the "information" within patterns of ultraweak $\left(\sim 10^{-12} \mathrm{~W} \cdot \mathrm{m}^{-2}\right)$ biogenic photon emissions from living cells may actually be the control stimuli that determine the integrity, dynamics and perhaps mortality of the cell [21]-[23]. We have noted that the optocoupler is particularly vulnerable to the rapid reversals from maximum-to-minimum values which would have been encountered with the geomagnetic signal because of the rapid alterations in maximum polarities. In other experiments replacement of optocouplers with the appropriate load capacity has resulted in the increased efficacy of slowing malignant cells growth when previously the diminishment was less or not different from sham field controls.

The fourth possibility, which is less palatable to many scientists and in many respects a challenge to the 
scientific tradition of maintained replicability, is the possibility there has been a change in the inertial frame or intrinsic space through which the earth as a component of the solar system is moving as it orbits the galaxy. Although potentially coincidental the disappearance of the MUKARB effect occurred at approximately the time the background radiant flux densities of photons that we measure continually by analogue photomultiplier tubes began to increase from the values of $\sim 10^{-12}$ to $10^{-11} \mathrm{~W} \cdot \mathrm{m}^{-2}$. Transient increases of the photon flux density by a factor of 10 about two weeks before very intense $(>8.0 \mathrm{M})$ seismic events anywhere on the planet have been measured [24]. However the PMT values always returned to baseline within a day or two after the seismic event. Since about July, 2012 we have measured a persistent rise in background photon power density from unknown sources [25].

That subtle changes associated with the solar cycle can affect chemical reactions has been known for more than a century. Takata [26] measured extensively the "flocculation index" in blood and discerned sunrise/sunset effects as well as latitude and solar rotational components. The famous Piccardi effect [27] whereby the precipitation measures for bismuth compounds followed the solar cycle is particularly relevant because these colloidal-like suspensions share many of the physical parameters such as viscosity with the cytoplasm and its interface with surface boundaries. Calculations indicate that the cell membrane's energy is predicted by mass interactions with the earth [28] and has the potential to be modulated by the subtle shifts in the energy across the membrane generated by the time-dependent changes in force as a function of lunar distance [29]. This relationship at a behavioural level was demonstrated repeatedly by Frank Brown, Jr and his colleagues decades ago [30]. Recently the global effects [31] of such "subtle forces and energies" were measured for photon emissions from seedlings that are similar over the surface of the planet [32].

Although cells contain intricately connected organelles the interfacial water properties along the inside and outside of the plasma membrane is also a special condition that exhibits unique properties [33] [34]. As shown repeatedly by Pollack and his colleagues [35], the viscosity of the water within the boundary interface (interfacial water) is increased by a factor of 10 compared to bulk water. The potential difference (voltage) from the resulting sheet of protons becomes equivalent to the traditional membrane potential attributed to extracellular-intracellular discrepancies of ion concentrations such as potassium [28]. Solutes remain excluded for protracted periods. This allows for a potential "condensate" like state where application of the appropriate temporally complex magnetic fields that simulate this resonance can be trapped within cohesive domains of water. Like a crystal state the convergence of temporal patterns towards the natural frequency could disintegrate the supportive structure.

\subsection{General Conclusion}

Kaiser [5] has recently revealed marked variability in the independent reproducibility between laboratories for cancer treatments and diagnostic tests. This persistent multivariate contribution from variables that have not been measured or even considered may be more prevalent than anticipated, particularly for treatments with physiologically-patterned magnetic fields. We suggest that the specific temporal-spatial configurations of these sequential magnetic fields should promote the coherence required for the "trapping" of the magnetic fields within the domains occupied by the intrinsic cytoskeleton that promotes its dissolution much like the superimposition of applied oscillations to the "natural frequency" of a suspension bridge can produce. However, any physical mechanism that disrupts the required conditions, such as mechanical perturbation, competitive EM fields, or alterations in precise timing, can prevent the effect. When this occurs, the cancer cells are not affected by the applied field. The phenomenon is analogous to the requirement for structural congruence between an exogenous ligand and the extracellular head group of a transmembrane protein for a response to occur. If the temporal "structure" of the applied field is not resonant with the malignant cells' cytostructural matrix because of obscuring sources, there is no effect.

\section{Acknowledgements}

Thanks to Dr. Blake T. Dotta for his expertise. We thank Dr. R. M. Lafrenie for the use of some of his equipment and supplies.

\section{References}

[1] Cifra, M., Fields, J.Z. and Farhadi, A. (2011) Electromagnetic Cellular Interactions. Progress in Biophysics and Molecular Biology, 105, 223-246. http://dx.doi.org/10.1016/j.pbiomolbio.2010.07.003 
[2] Blank, M. and Goodman, R. (1997) Do Electromagnetic Fields Interact Directly Interact with DNA? Bioelectromagnetics, 18, 111-115. http://dx.doi.org/10.1002/(SICI)1521-186X(1997)18:2<111::AID-BEM3>3.0.CO;2-5

[3] Blank, M. and Soo, L. (2001) Electromagnetic Acceleration of Transfer Reactions. Journal of Cellular Biochemistry, 81, 278-283. http://dx.doi.org/10.1002/1097-4644(20010501)81:2<278::AID-JCB1042>3.0.CO;2-F

[4] Pilla, A.A., Muehsam, D.J., Markov, M.S. and Sisken, B.F. (1999) EMF Signals and Ion/Ligand Binding Kinetics: Prediction of Bioeffective Waveform Parameters. Bioelectrochemistry and Bioenergetics, 48, 27-34. http://dx.doi.org/10.1016/S0302-4598(98)00148-2

[5] Kaiser, J. (2015) The Cancer Test: A Nonprofit's Effort to Replicate 50 Top Cancer Papers Is Shaking up Labs. Science, 348, 1411-1413. http://dx.doi.org/10.1126/science.348.6242.1411

[6] Barbault, A., Costa, F.P., Bottger, B., Munden, R.F., Bomholt, F., Kuster, N. and Pasche, B. (2009) Amplitude-Modulated Electromagnetic Fields for the Treatment of Cancer: Discovery of Tumor-Specific Frequencies and Assessment of a Novel Therapeutic Approach. Journal of Experimental \& Clinical Cancer Research, 28, 1-10. http://dx.doi.org/10.1186/1756-9966-28-51

[7] Crocetti, S., Beyer, C., Schade, G., Egli, M., Froehlich, J. and Franco-Obregon, A. (2013) Low Intensity and Frequency Pulsed Electromagnetic Fields Selectively Impair Breast Cancer Cell Viability. PLoS ONE, 8, e72944. http://dx.doi.org/10.1371/journal.pone.0072944

[8] Hu, J.H., St-Pierre, L.S., Buckner, L.S., Lafreniere, R.M. and Persinger, M.A. (2010) Suppression of Growth of Injected Melanoma Cells by Whole Body Exposure to Specific Spatial-Temporal Configurations of Weak Intensity Magnetic Fields. International Journal of Radiation Biology, 86, 79-88. http://dx.doi.org/10.3109/09553000903419932

[9] Murugan, N.J., Karbowsk, L.M., Lafrenie, R.M. and Persinger, M.A. (2013) Temporally-Patterned Magnetic Fields Induce Complete Fragmentation in Planaria. PLoS ONE, 8, e61714. http://dx.doi.org/10.1371/journal.pone.0061714

[10] Buckner, C.A., Buckner, A.L., Koren, S.A., Persinger, M.A. and Lafrenie, R.M. (2015) Inhibition of Cancer Cell Growth by Exposure to a Specific Time-Varying Electromagnetic Field Involves T-Type Calcium Channels. PLoS ONE. http://dx.doi.org/10.1371/journal.pone.0124136

[11] Martin, L.J., Koren, S.A. and Persinger, M.A. (2004) Thermal Analgesic Effects from Weak, Complex Magnetic Fields and Pharmacological Interactions. Pharmacology Biochemistry and Behavior, 78, 217-227. http://dx.doi.org/10.1016/j.pbb.2004.03.016

[12] St-Pierre, L.S., Mazzuchin, A. and Persinger, M.A. (2008) Altered Blood Chemistry and Hippocampal Histomorphology in Adult Rats Following Prenatal Exposure to Physiologically-Patterned, Weak (50-500 NanoTesla Range) Magnetic Fields. International Journal of Radiation Biology, 84, 325-335. http://dx.doi.org/10.1080/09553000801953300

[13] McKay, B.E. and Persinger, M.A. (2003) Complex Magnetic Fields Potentiate Agmatine-Mediate Contextual Fear Learning Deficits in Rats. Life Science, 72, 2489-2498. http://dx.doi.org/10.1016/S0024-3205(03)00140-1

[14] Thomas, W., Kavaliers, M., Prato, F.S. and Ossenkopp, K.-P. (1997) Antinoceptive Effects of a Pulsed Magnetic Field in the Land Snail, Cepaeanemoralis. Neuroscience Letters, 222, 107-110. http://dx.doi.org/10.1016/S0304-3940(97)13359-6

[15] Persinger, M.A., Bureau, Y.R.J., Kostaskos, M., Peredery, O. and Falter, H. (1993) Behaviors of Rats with Insidious Multifocal Brain Damage Induced by Seizures Following Single Peripheral Injections of Lithium and Pilocarpine. Physiology \& Behavior, 53, 849-866. http://dx.doi.org/10.1016/0031-9384(93)90261-d

[16] Lado, W.E. and Persinger, M.A. (2012) Spatial Memory Deficits and Their Correlations with Clusters of Shrunken Neuronal Soma in the Cortices and Limbic System Following a "Mild" Mechanical Impact to the Dorsal Skull in Female Rats. Journal of Behavioral and Brain Science, 2, 333-342. http://dx.doi.org/10.4236/jbbs.2012.23038

[17] Povlishock, J.T. and Coburn, T.H. (1989) Morphopathological Change Associated with Mild Head Injury. In: Levin, H.S., Eisenberg, H.M. and Benton, A.L., Eds., Mild Head Injury, Oxford University Press, New York, 37-53.

[18] Verdel, N. and Bukovec, P. (2014) Possible Further Evidence for the Thixotropic Phenomenon of Water. Entropy, 16, 2146-2160. http://dx.doi.org/10.3390/e16042146

[19] Murugan, N.J., Karbowski, L.M., Lafrenie, R.M. and Persinger, M.A. (2015) Maintained Exposure to Spring Water but Not Double Distilled Water in Darkness and Thixotropic Conditions to Weak $((\sim 1 \mu \mathrm{T})$ Temporally Patterned Magnetic Fields Shift Photon Spectroscopic Wavelengths: Effects of Different Shielding Materials. Journal of Biophysical Chemistry, 6, 14-28. http://dx.doi.org/10.4236/jbpc.2015.61002

[20] Koren, S.A., Bosarge, W.E. and Persinger, M.A. (2015) Magnetic Fields Generated by Optical Coupler Circuits May Also Be Containment Loci for Entanglement of P-N Junction-Plasma Cell Membrane Photons within Exposed Living Systems. International Letters of Chemistry, Physics and Astronomy, 3, 84-105.

[21] Dotta, B.T., Murugan, N.J., Karbowski, L.M., Lafrenie, R.M. and Persinger, M.A. (2014) Shifting Wavelengths of U1tra-Weak Photon Emissions from Dying Melanoma Cells: Their Chemical Enhancement and Blocking Are Predicted by Cosic's Theory Resonant Recognition Model for Macromolecules. Naturwissenschaften, 101, 87-94. 
http://dx.doi.org/10.1007/s00114-013-1133-3

[22] Fels, D. (2009) Cellular Communication through Light. PloS ONE, 4, e5086. http://dx.doi.org/10.1371/journal.pone.0005086

[23] Trushin, M.V. (2004) Light-Mediated "Conversation" among Microorganisms. Microbiological Research, 159, 1-10. http://dx.doi.org/10.1016/j.micres.2003.11.001

[24] Persinger, M.A., Lafreniere, G.F. and Dotta, B.T. (2012) Marked Increases in Background Photon Emissions in Sudbury, Ontario More than Two Weeks before the Magnitude > 8.0 Earthquakes in Japan and Chile. International Journal of Geosciences, 3, 627-629. http://dx.doi.org/10.4236/ijg.2012.33062

[25] Persinger, M.A., Lehman, B., Dotta, B.T. and Lafreniere, G.F. (2015) Four Years of Daily Photon Emissions That Have Predicted Major Earthquakes: Raw Data, Spectral Power Density Analyses and Implications for Geosciences. International Journal of Geosciences, 6, 311-316. http://dx.doi.org/10.4236/ijg.2015.64024

[26] Takata, M. (1951) Über eine neue biologisch wirksame Komponente der Sonnenstrahlung. Archiv für Meteorologie, Geophysik und Bioklimatologie Serie B, 2, 486-508. http://dx.doi.org/10.1007/BF02242701

[27] Piccardi, G. (1962) Chemical Basis of Medical Climatology. C. C. Thomas, Springfield.

[28] Persinger, M.A. and Lafrenie, R.M. (2014) The Cancer Cell Plasma Membrane Potentials as Energetic Equivalents to Astrophysical Properties. International Letters of Chemistry, Physics and Astronomy, 17, 67-77. http://dx.doi.org/10.18052/www.scipress.com/ILCPA.17.67

[29] Persinger, M.A. (2014) Terrestrial and Lunar Gravitational Forces upon the Mass of a Cell: Relevance to Cell Function. International Letters of Chemistry, Physics and Astronomy, 2, 15-21.

[30] Brown Jr., F.A. and Chow, C.S. (1973) Interorganismic and Environmental Influences through Extremely Weak Electromagnetic Fields. The Biological Bulletin, 144, 437-461.

[31] Berzhanskaya, L.Y., Berzhanskii, V.N., Beloptovota, O.Y., Pil'nikova, T.G. and Metlyayev, T.N. (1995) Bacterial Bioluminescent Activity as a Pointer to Geomagnetic Disturbances. Biophysics, 40, 761-764.

[32] Moraes, T.A., Barlow, P.W., Kingele, E. and Gallep, C.M. (2012) Spontaneous Ultra-Weak Light Emissions from Wheat Seedlings Are Rhythmic and Synchronized with the Time Profile of the Local Gravimetric Tide. Naturwissenschafen, 99, 465-472. http://dx.doi.org/10.1007/s00114-012-0921-5

[33] Del Giudice, E., Spinetti, P.S. and Tedeschi, A. (2010) Water Dynamics at the Root of Metamorphosis in Living Organisms. Water, 2, 566-586. http://dx.doi.org/10.3390/w2030566

[34] Karbowski, L.M. and Persinger, M.A. (2015) Variable Viscosity of Water as the Controlling Factor in Energetic Quantities That Control Living Systems: Physicochemical and Astronomical Interactions. International Letters of Chemistry, Physics and Astronomy, 4, 1-9. http://dx.doi.org/10.18052/www.scipress.com/ILCPA.43.1

[35] Pollack, G.H., Figuerora, X. and Zhao, Q. (2009) Molecules, Water, and Radiant Energy: New Clues for the Origin of Life. International Journal of Molecular Sciences, 10, 1419-1429. http://dx.doi.org/10.3390/ijms10041419 